\title{
Knowledge and attitude towards epilepsy among rural residents in southern Ethiopia: a cross-sectional study
}

\author{
Alemayehu Molla ${ }^{1 *}$ (D), Birhanie Mekuriaw ${ }^{1}$, Endashaw Habtamu ${ }^{1}$ and Moges Mareg²
}

\begin{abstract}
Background: Although epilepsy is one of the most prevalent neurological problems, it is highly surrounded by stigma and prejudice, which results in negative attitude towards the illness. Due to numerous misconceptions and beliefs attributed towards epilepsy, most people in rural communities have poor understanding and perception about epilepsy. Studying knowledge and attitude of this major neurologic problem among rural residents is crucial to add knowledge and show area of interventions. Therefore, the aim of this study was to assess the knowledge and attitude towards Epilepsy among rural residents in Ethiopia.

Methods: This was a community based cross-sectional study conducted in rural parts of Gedeo zone, Southern Ethiopia. A total of 732 randomly selected adult residents were interviewed using a pre-tested questionnaire. The collected data were entered to Epi-data version 3.1 and analyzed using SPSS version 20. Descriptive statistics and logistic regressions were performed. Multivariable binary logistic regression analysis was conducted to determine the presence of a statistically significant association between explanatory variables and outcome variables at corresponding $95 \% \mathrm{Cl}$.
\end{abstract}

Results: The magnitude of poor knowledge and unfavorable attitude towards epilepsy were 27.0 and 51.6\%, respectively. Participants who can't read and write, having stigma related to epilepsy, participants who did not live with epileptic patients; unfavorable attitude and age were factors associated with poor knowledge towards epilepsy. On the other hand, Stigma related to epilepsy, poor knowledge, age and perceiving epilepsy as a God punishment for sinful activities were variables significantly associated with unfavorable attitude of epilepsy.

Conclusions: There is a gap regarding the knowledge and attitude towards epilepsy among community residents in southern Ethiopia. This demonstrates a need for community educational program regarding epilepsy which can increase community awareness particularly in rural areas to decrease stigma and negative beliefs towards epilepsy.

Keywords: Attitude, Epilepsy, Ethiopia, Knowledge, Rural communities

\footnotetext{
* Correspondence: alexmolla09@gmail.com

'Department of Psychiatry, College of Health and Medical Science, Dilla University, Dilla, Ethiopia

Full list of author information is available at the end of the article
}

(c) The Author(s). 2021 Open Access This article is licensed under a Creative Commons Attribution 4.0 International License, which permits use, sharing, adaptation, distribution and reproduction in any medium or format, as long as you give appropriate credit to the original author(s) and the source, provide a link to the Creative Commons licence, and indicate if changes were made. The images or other third party material in this article are included in the article's Creative Commons licence, unless indicated otherwise in a credit line to the material. If material is not included in the article's Creative Commons licence and your intended use is not permitted by statutory regulation or exceeds the permitted use, you will need to obtain permission directly from the copyright holder. To view a copy of this licence, visit http://creativecommons.org/licenses/by/4.0/ The Creative Commons Public Domain Dedication waiver (http://creativecommons.org/publicdomain/zero/1.0/) applies to the data made available in this article, unless otherwise stated in a credit line to the data. 


\section{Background}

Neuropsychiatry disorders account more than a quarter of the global burden of diseases [1]. Epilepsy is one of the known neurological disorders characterized by repeated seizures and with at least two unprovoked seizure episodes [2]. The impact of epilepsy in terms of poor quality of life, morbidity, mortality, and stigma varies worldwide depending on economic, cultural, and health backgrounds of communities [3]. Epilepsy remains a major public health problem with its social, cultural, psychological and economic effects $[4,5]$.

Misperceptions and indigenous beliefs about the causes and inheritability of epilepsy make the lives of people with epilepsy (PWE) more difficult, particular in low and middle income countries (LMIC) [6]. Besides, stigma related to epilepsy is common in developing countries, and its social, psychological and economic consequences become a major public health problems $[4,7]$. The religious and cultural beliefs have wide ranges of effects on treatment options and the adherence level among people with epilepsy [7]. Socio-cultural beliefs cause a negative impact to patients with epilepsy in many developing nations [8]. For instance, many people in developing countries believe that epilepsy is caused by witchcraft or evil spirits, and treatment should be through the use of traditional healing practice and religious leaders [8-10].

About $81 \%$ of PWE and their relatives affected from perceived stigma related to epilepsy in Ethiopia [11]. Such unfavorable attitudes and beliefs had serious negative social and psychological impact for PWE such as fear, and decrement in social interactions [12].

Traditional and supernatural perceptions also can have a great negative influence on the treatment delay and adherence of people with epilepsy. For instance, in developing countries, 60 to $90 \%$ of people with epilepsy receive no treatment due to negative beliefs regarding epilepsy [4, 13]. As a result, people with epilepsy are affected by a multitude of social, economic and psychological problems of stigmatization and lead to poor quality of life for people with epilepsy $[14,15]$.

It is important that investigation of the communities perception and attitude towards epilepsy helps to demystify individual and familial beliefs regarding the disease and to reduce the emotional impact of having a seizure in front of others $[12,16]$. Although knowledge and attitudes regarding epilepsy were assessed in Ethiopia, their focus was among students and residents living in the towns $[8,17]$ and it is not well investigated among community residents. The current study aimed to assess community knowledge and attitude towards epilepsy among rural residents in Gedeo Zone, Southern Nation Nationalities and Peoples Region (SNNPR), Ethiopia.
Finding of the study will have valuable contribution in the current state of knowledge by providing appropriate evidences which will be important for decision makers, politicians, health personnel and future researchers.

\section{Methods and materials Study design}

This was a community based cross sectional study conducted from March 1 to March 30, 2019.

\section{Study setting}

The study was conducted in rural community residents of Gedeo zone residents. Gedeo is one of the eleven zones found in SNNPR with the administrative center of Dilla town located $360 \mathrm{~km}$ away from Addis Ababa (the capital city of Ethiopia). Gedeo zone has six rural districts and two administrative towns (Dilla and Yirgachefe). The 2007 census conducted by the central statistical agency of Ethiopia reported that the zone has a total population of $1,086,768$ with $532,516(49 \%)$ men and 554, 225 (51\%) women [18]. More than 179,677 households were counted with the average 5 person living in each household and total of 276 health facilities were found in the zone [19]. People from multiple ethnic backgrounds are living in Gedeo zone. One special characteristics of this zone is that most of community residents use two leg motor bicycles which magnifies risk of head injury, one of the expected cause for epilepsy [20, 21].

\section{Study subjects}

All permanent residents (living in the area for at least six months) with age 18 years and above and avail during data collection period were study subjects. Individuals who were severely ill during data collection time and unable to communicate were excluded from the study.

\section{Sampling size and procedure}

Sample size was calculated by using a single population proportion formula; considering $66.5 \%$ of residents have poor practice towards epilepsy (study conducted in western parts of Ethiopia [8]) and margin of error 5\%. After using design effect of 2 and inflating sample size by $10 \%$ to account for non- response rate, the final sample size was 755. Multistage sampling technique was applied to select study participants. In the first stage, 3 districts were selected out of six rural districts in Gedeo zone using lottery method. Then, random selections of $3 \mathrm{sub}$ districts from each selected district was employed. The number of residents and households list for each of the selected sub district were obtained from corresponding district offices and health extension workers. Accordingly, the calculated sample size was proportionally 
allocated to the selected sub districts and one individual was interviewed from each household consecutively till the sample size was addressed.

\section{Data collection instruments}

Data was collected by interview using pretested questionnaires. The contents of the questionnaire included independent variables like socio demographic characteristics, psychosocial factors, clinical variables and outcome variables knowledge and attitude towards Epilepsy. The outcome variables were assessed by knowledge and attitude related questions. Knowledge towards epilepsy was assessed using researcher prepared questions based on previous similar studies [17] and cultural context of study area and it has "yes" or "no" options towards epilepsy. It includes general information towards epilepsy, common manifestations and expected causes; in this case about $27 \%$ of participants reported as they had poor knowledge towards epilepsy. Attitude was assessed using 7-item questionnaires after modifying Kilifi epilepsy beliefs and attitude scale in our cultural context. The questionnaire includes attitude of respondents about employment opportunity, marital prospects, educational ability, believing epilepsy is result of punishment from God due to wrong doing, chance of cure by modern medicine and attitude of the respondents towards living with epileptic patient $[8,9,22-24]$. We used the following options for each question: $1=$ strongly disagree, $2=$ disagree, $3=$ agree, $4=$ strongly agree. We categorized participants as with favorable and unfavorable attitude based on the mean score which was 51.6.

Epilepsy stigma was assessed by using 24 item epilepsy stigma scales, participants were asked to choice suitable answer among following options: $1=$ not at all, $2=$ a little, $3=$ a lot, $4=$ totally. Finally all possible answers were summed and mean score was used to identify participants if they had stigma or not [25]. The internal consistence (cronbach alpha) of 24-item Epilepsy stigma scale in current study is 0.81 .

\section{Data quality assurance}

The questionnaire was first prepared in English and translated to local languages (Gedeo'fa and Amharic) and back translation to English was done to check its consistency. Data was collected by 9 BSc nurses and supervised by 3 MSc level psychiatry professionals. Two days training was given to data collectors and supervisors. Pre-test was done on $5 \%(n=38)$ of participants. Based on the finding of the pretest, the questionnaire was revised and the expressions of some contents were rephrased to make it easier to be understood by study subjects. The data collectors were supervised daily and the filled questionnaires were checked daily by the supervisors and investigators for its completeness.

\section{Data analysis procedure}

The coded data was entered to Epi-data 3.1 and analyzed using SPSS version 20. Data was presented using frequencies and percentages. Bivariate binary logistic regression analysis was conducted to determine each independent variables and variables with $p$-value less than 0.2 were entered to multivariate analysis. Multivariate binary logistic regression analysis was performed to identify statistically associated variables with outcome variables. Finally, variables with $P$ values less than 0.05 were considered statistically significant and strength of the association was presented by adjusted odds ratio with corresponding 95\% C.I.

\section{Results}

Socio-demographic distribution of the respondents

A total of 732 participants were included in the study with the response rate of $97 \%$. The mean age $( \pm S D)$ of the respondents was $33( \pm 11.3)$ years, with age range of 18-70 years. Among the total respondents, a majority were in age range of $18-28$ years $316(43.2 \%)$ and 467 (63.8\%) were male participants. The largest proportion of the participants, 513 (70.1\%) were protestant religion follower, and 632(86.3\%) were Gedeo in their ethnicity (Table 1).

\section{Psychosocial and clinical related factors of respondents}

Regarding the psychosocial characteristics of the respondents, $347(47.4 \%)$ of participants reported stigma related to epilepsy and more than half reported that they have poor social support 451 (61.6\%). About 54 (7.4\%) respondents reported history of epilepsy, but only 12 $(1.6 \%)$ of them got help for their problem (Table 2).

\section{Knowledge and attitude related factors towards epilepsy} Among participants, 198 (27\%) of respondents had no information about epilepsy. Regarding to the source of information, large numbers 274 (37.4\%) of them heard from their friends. Of the total participants, 49 (6.7\%) reported as they were living with epileptic patients in one house and about $154(21 \%)$ have history of witnessing seizure. Participants response regarding the cause of epilepsy showed that majorities 274 (37.4\%) of them perceived that epilepsy is a punishment from the God for sin. Concerning to the symptoms of epilepsy, large numbers of participants $592(80.9 \%)$ reported convulsion as a symptom of epilepsy followed by loss of consciousness 407 (55.6\%). Regarding to the overall attitude of participants towards epilepsy, about 378 (51.6\%) had unfavorable attitude (Table 3). 
Table 1 Distribution of socio-demographic factors in rural Gedeo zone, Ethiopia, $2019(n=732)$

\begin{tabular}{|c|c|c|c|}
\hline Variable & Categories & Frequency & Percent (\%) \\
\hline \multirow[t]{4}{*}{ Age } & $18-28$ years & 316 & 43.2 \\
\hline & 29-39 years & 231 & 31.6 \\
\hline & $40-50$ years & 112 & 15.3 \\
\hline & $>50$ years & 73 & 10.0 \\
\hline \multirow[t]{2}{*}{ Sex } & Male & 467 & 63.8 \\
\hline & Female & 265 & 36.2 \\
\hline \multirow[t]{5}{*}{ Religion } & Protestant & 513 & 70.1 \\
\hline & Orthodox & 117 & 16.0 \\
\hline & Muslim & 42 & 5.7 \\
\hline & Catholic & 40 & 5.5 \\
\hline & Others $^{a}$ & 20 & 2.7 \\
\hline \multirow[t]{5}{*}{ Marital status } & Married & 513 & 70.1 \\
\hline & Single & 147 & 20.1 \\
\hline & Widowed & 35 & 4.8 \\
\hline & Divorced & 25 & 3.4 \\
\hline & Separated & 12 & 1.6 \\
\hline \multirow[t]{5}{*}{ Ethnicity } & Gedeo & 632 & 86.3 \\
\hline & Oromo & 45 & 6.1 \\
\hline & Amhara & 28 & 3.8 \\
\hline & Gurage & 20 & 2.7 \\
\hline & Others $^{\mathrm{b}}$ & 8 & 1.1 \\
\hline \multirow[t]{5}{*}{ Educational level } & Can't read and write & 196 & 26.8 \\
\hline & Primary & 276 & 37.7 \\
\hline & Secondary & 151 & 20.6 \\
\hline & Preparatory & 51 & 7.0 \\
\hline & College and above & 58 & 7.9 \\
\hline \multirow[t]{7}{*}{ Occupational status } & Government employed & 96 & 13.1 \\
\hline & Farmer & 232 & 31.7 \\
\hline & Merchant & 105 & 14.3 \\
\hline & Private employed & 116 & 15.8 \\
\hline & House wife & 94 & 12.8 \\
\hline & Daily laborer & 24 & 3.3 \\
\hline & Others $^{c}$ & 65 & 8.9 \\
\hline \multirow[t]{2}{*}{ Distance to health center $(\mathrm{km})$} & $<10 \mathrm{~km}$ & 718 & 98.1 \\
\hline & $\geq 10 \mathrm{~km}$ & 14 & 1.9 \\
\hline \multirow[t]{2}{*}{ Average monthly income } & $<1539$ ETB & 538 & 73.5 \\
\hline & $\geq 1539$ ETB & 194 & 26.5 \\
\hline
\end{tabular}

Joba witness \& no religion, ${ }^{\mathrm{b}}$ Tigre, Wolaita \& Silte, ${ }^{\mathrm{c}}$ Jobless \& Students

Factors associated with knowledge status towards epilepsy

In the multivariate logistic regression analysis, participants who cannot read and write, having stigma related to epilepsy, participants without history of living with epileptic patients, age and unfavorable attitude towards epilepsy were variables statistically associated with poor knowledge about epilepsy at $P$-value less than 0.05 (Table 4).

Accordingly, those who could not read and write [AOR $=6.34,(95 \% \mathrm{CI}: 2.66,15.10)]$, no history of living with epileptic patients $[\mathrm{AOR}=10.15,(95 \% \mathrm{CI}: 2.25$, $45.80)$ ], age range of $18-28$ [AOR $=2.60$ (95\% CI: 1.13 , 5.94)], age groups of $29-39$ [AOR $=5.94$, (95\% CI: 2.63, 
Table 2 Description of psychosocial and clinical factors among rural residents, in Gedeo zone 2019 ( $n=732$ )

\begin{tabular}{|c|c|c|c|}
\hline Variables & Categories & Frequency & Percent (\%) \\
\hline \multirow[t]{2}{*}{ Stigma related to epilepsy } & Yes & 347 & 47.4 \\
\hline & No & 385 & 52.6 \\
\hline \multirow[t]{3}{*}{ Social support } & Poor & 451 & 61.6 \\
\hline & Moderate & 249 & 34.0 \\
\hline & Strong & 32 & 4.4 \\
\hline \multirow[t]{2}{*}{ History of epilepsy } & Yes & 54 & 7.4 \\
\hline & No & 678 & 92.6 \\
\hline \multirow[t]{2}{*}{ Get help for illness } & Yes & 12 & 1.6 \\
\hline & No & 720 & 98.4 \\
\hline \multirow[t]{3}{*}{ Place of treatment } & Health institutions & 2 & 16.7 \\
\hline & Religious centers & 7 & 58.3 \\
\hline & Traditional healers & 3 & 25.0 \\
\hline \multirow[t]{3}{*}{ Reason not to get help } & No treatment & 31 & 73.8 \\
\hline & No money & 1 & 2.4 \\
\hline & Does not need treatment & 10 & 23.8 \\
\hline \multirow[t]{2}{*}{ Family history of epilepsy } & Yes & 61 & 8.3 \\
\hline & No & 671 & 91.7 \\
\hline \multirow[t]{2}{*}{ Family history of mental illness } & Yes & 76 & 10.4 \\
\hline & No & 656 & 89.6 \\
\hline \multirow[t]{2}{*}{ Previous history of head injury } & Yes & 58 & 7.9 \\
\hline & No & 674 & 92.1 \\
\hline
\end{tabular}

13.42)], unfavorable attitude $[\mathrm{AOR}=2.32,(95 \% \mathrm{CI}, 1.56$, $3.44)]$, and epilepsy related stigma $[\mathrm{AOR}=1.90,(95 \% \mathrm{CI}$, $1.28,2.80)]$ were variables found statistical significant with poor knowledge towards epilepsy (Table 4).

\section{Factors associated with attitude towards epilepsy among} rural geode zone residents

In multivariate binary logistic regression analysis, stigma related to epilepsy, poor knowledge, age and perceiving that epilepsy as a God punishment for a sin were variables statistically associated with unfavorable attitude.

Participants with poor knowledge $[\mathrm{AOR}=1.78$, $(95 \%$ CI: $1.18,2.69)]$, perceived epilepsy stigma $[\mathrm{AOR}=1.54$, (95\% CI: $1.11,2.15)$ ], age range of $29-39$ [AOR $=2.14$, (95\% CI: $1.45,3.16)]$, age $>50 \quad[\mathrm{AOR}=2.35$, (95\% CI: $1.34,4.14)]$ and considering epilepsy as a God punishment for a $\sin [\mathrm{AOR}=1.81$, (95\% CI: 1.28, 2.52)], were variables significantly associated with unfavorable attitude among residents of southern Ethiopia (Table 5).

\section{Discussion}

In Ethiopia, there are different studies reporting epilepsy as a major problem within the country [8, 17]. The knowledge and attitude of people regarding epilepsy is not well addressed and even the available studies are mainly focused on college students, health professionals, teachers and medical students. Therefore, this study was intended to address this gap by assessing the knowledge and attitude of rural community residents towards epilepsy in Ethiopia.

The current study showed that about $27.0 \%$ participants had poor knowledge and $51.6 \%$ had unfavorable attitude towards epilepsy. Regarding the level of poor knowledge, the finding was lower than studies in Nigeria 43-50\% [26, 27], Sudan47\% [28] and north Thailand 80-99 [29]. However, our finding showed a higher magnitude of poor knowledge than the institutional study conducted in Ethiopia 14.3\% [17]. The possible reason for the variation might be the difference in study design, socio cultural characteristics of the participants and study period. The other possible justifications for the difference might be the variation in study setting and populations in which the other study was conducted among students as they are more nearby for health information regarding epilepsy which attributes to decrease the magnitude of poor knowledge than community residents. Furthermore, indigenous beliefs or myths regarding epilepsy are usually common among less/none educated and community residents which can be a reason for the difference for the level of knowledge in between a group of population. 
Table 3 Distribution of Knowledge and Attitude related variables towards Epilepsy among rural residents, in Gedeo zone 2019 ( $\mathrm{n}=$ 732)

\begin{tabular}{|c|c|c|c|}
\hline Variables & Categories & Frequency & Percent (\%) \\
\hline \multirow[t]{2}{*}{ Have information about epilepsy } & Yes & 534 & 73.0 \\
\hline & No & 198 & 27.0 \\
\hline \multirow[t]{4}{*}{ Source of information } & Health professionals & 150 & 20.5 \\
\hline & Media & 90 & 12.3 \\
\hline & Friends & 274 & 37.4 \\
\hline & Others & 35 & 4.8 \\
\hline \multirow[t]{2}{*}{ Live with Epileptic patient } & Yes & 49 & 6.7 \\
\hline & No & 683 & 93.3 \\
\hline \multirow[t]{2}{*}{ Witnessing seizure } & Yes & 154 & 21.0 \\
\hline & No & 578 & 79.0 \\
\hline \multirow[t]{2}{*}{ Perceiving epilepsy as punishment for sin } & Yes & 274 & 37.4 \\
\hline & No & 458 & 62.6 \\
\hline \multirow[t]{2}{*}{ Perceiving Substance is a cause for epilepsy } & Yes & 82 & 11.2 \\
\hline & No & 650 & 88.8 \\
\hline \multirow[t]{2}{*}{ Head injury as cause of epilepsy } & Yes & 212 & 29.0 \\
\hline & No & 520 & 71.0 \\
\hline \multirow[t]{2}{*}{ Convulsion as a symptoms of epilepsy } & Yes & 592 & 80.9 \\
\hline & No & 140 & 19.1 \\
\hline \multirow[t]{2}{*}{ Loss of consciousness as symptom of epilepsy } & Yes & 407 & 55.6 \\
\hline & No & 325 & 44.4 \\
\hline \multirow[t]{2}{*}{ Others as symptoms of epilepsy ${ }^{k}$} & Yes & 34 & 4.6 \\
\hline & No & 698 & 95.4 \\
\hline \multirow[t]{2}{*}{ Attitude towards epilepsy } & favorable attitude & 354 & 48.4 \\
\hline & unfavorable attitude & 378 & 51.6 \\
\hline \multirow[t]{2}{*}{ I can marry epileptic patients } & Agree & 148 & 20.2 \\
\hline & Disagree & 584 & 78.8 \\
\hline \multirow[t]{2}{*}{ Epilepsy is curable } & agree & 488 & 66.7 \\
\hline & disagree & 224 & 33.3 \\
\hline \multirow[t]{2}{*}{ I can be a neighbor with epileptic patients } & Agree & 569 & 77.7 \\
\hline & Disagree & 163 & 22.3 \\
\hline \multirow[t]{2}{*}{ I can Employ epileptics patients } & Agree & 466 & 63.4 \\
\hline & Disagree & 268 & 36.6 \\
\hline
\end{tabular}

k- Unknown and irritability

On the other hand, $51.6 \%$ of respondents reported unfavorable attitude. The finding was consistent with studies conducted in north Thailand which concludes negative attitude ranged 4-90\% [29], Nigeria 55\% [27], and Ethiopia in which about $51.6 \%$ belief epilepsy is a kind of insanity [17]. However, it was lower than studies conducted in Nigeria 100\% respondents would not allow marriage of epileptic patients [27], Nigeria $87.2 \%$ would not employ epileptic patients, but it was higher than study done in Ethiopia 35.5\% [8], china 42.1\% [30], Jordan 9\% [31],Vietnam (33\%) [32] and Egypt (8\%) [33]. The possible reason might be most of the populations in developing countries are marginalized in society as a result of negative public attitudes towards Epilepsy due to stigmas which is prevalent in cultures [32]. Another explanation might be developing countries most of the time consider the cause and treatment option for epilepsy are connected to natural methods and traditional perspectives [34]. It might be also due to difference in study area, in which most of previously done studies including our country were limited to institutions such as colleges and universities, but current study is done in previously undressed rural area on knowledge 
Table 4 Bivariate and multivariate logistic regression analysis of associated factors for poor. Knowledge towards Epilepsy among rural Gedeo zone residents, 2019

\begin{tabular}{|c|c|c|c|c|c|}
\hline \multirow[t]{2}{*}{ Explanatory variables } & \multirow[t]{2}{*}{ Categories } & \multicolumn{2}{|c|}{ Knowledge } & \multirow[t]{2}{*}{ COR, $(95 \% \mathrm{Cl})$} & \multirow[t]{2}{*}{ AOR, $(95 \% \mathrm{Cl})$} \\
\hline & & $\begin{array}{l}\text { Poor } \\
\text { n(\%) }\end{array}$ & $\begin{array}{l}\text { Good } \\
\mathrm{n}(\%)\end{array}$ & & \\
\hline \multirow[t]{2}{*}{ Sex } & Male & $111(15.2)$ & $356(48.6)$ & Referent & Referent \\
\hline & Female & $87(11.9)$ & $178(24.3)$ & $1.57,(1.12,4.31)$ & $1.02(0.68,1.53)$ \\
\hline \multirow[t]{5}{*}{ Educational status } & Cannot read and write & $90(12.3)$ & $106(14.5)$ & $4.60,(2.15,9.93)$ & $6.34,(2.66,15.10)^{* *}$ \\
\hline & Primary & $62(8.5)$ & $214(29.3)$ & $1.58,(0.73,3.39)$ & $1.45,(0.63,3.34)$ \\
\hline & Secondary & $31(4.2)$ & $120(16.4)$ & $1.41,(0.62,3.17)$ & $1.69,(0.71,4.07)$ \\
\hline & Preparatory & $6(0.8)$ & $45(6.2)$ & $0.73,(0.24,2.20)$ & $0.81,(0.25,2.66)$ \\
\hline & College and above & $9(1.2)$ & $49(6.7)$ & Referent & Referent \\
\hline \multirow[t]{2}{*}{ living with epileptic patients } & Yes & $2(0.3)$ & $47(6.4)$ & Referent & Referent \\
\hline & No & $196(26.8)$ & $487(66.5)$ & $9.46(2.28,39.3)$ & $11.15,(2.25,45.80)^{* *}$ \\
\hline \multirow[t]{2}{*}{ Family history of epilepsy } & Yes & $8(1.1)$ & $53(7.2)$ & Referent & Referent \\
\hline & No & $190(26.0)$ & $481(65.7)$ & $2.62(1.2,5.61)$ & $1.48,(0.59,3.70)$ \\
\hline \multirow[t]{2}{*}{ Family mental illness } & Yes & $13(1.8)$ & $63(8.6)$ & Referent & Referent \\
\hline & No & $185(25.3)$ & $471(64.3)$ & $1.91(1.02,3.54)$ & $1.05,(0.52,2.12)$ \\
\hline \multirow[t]{2}{*}{ Stigma related to epilepsy } & Yes & $128(17.5)$ & $219(29.9)$ & $2.63(1.88,3.7)$ & $1.90,(1.28,2.80)^{* *}$ \\
\hline & No & $70(9.6)$ & $315(43.0)$ & Referent & Referent \\
\hline \multirow[t]{4}{*}{ Age } & $18-<=28$ years & $62(8.5)$ & $254(34.7)$ & $1.54(0.75,3.17)$ & $2.60,(1.13,5.94)^{*}$ \\
\hline & $29-<=38$ years & $108(14.8)$ & $123(16.8)$ & $5.53(2.71,11.3)$ & $5.94(2.63,13.42)^{* *}$ \\
\hline & $39-<=50$ years & $18(2.5)$ & $94(12.8)$ & $1.21(0.52,2.78)$ & $1.22(0.49,3.03)$ \\
\hline & $>50$ years & $10(1.4)$ & $63(8.6)$ & Referent & Referent \\
\hline \multirow[t]{2}{*}{ Attitude } & Unfavorable & $140(19.1)$ & $238(32.5)$ & $3.02(2.12,4.26)$ & $2.32,(1.56,3.44)^{* *}$ \\
\hline & favorable & $58(7.9)$ & $296(40.4)$ & Referent & Referent \\
\hline
\end{tabular}

*significant variable $(p$-value $<0.01)$, ** statistically significant variables ( $p$-value $<0.05)$

$\mathrm{n}(\%)=$ frequency and percentage

and attitude towards this commonly occurring neurological problem in our country.

The second objective of our study was to identify factors associated with poor knowledge and unfavorable attitudes. Participants who could not read and write were more likely to have poor knowledge as compared with college and above graduates and this was supported by study conducted in Jordan [31], systematic review study done in different countries [35-39] and other study done in Nigeria [40], Sudan [28] and Ethiopia [8]. The possible explanation might be due to the difference in the educational level which affects their ability to understand and perceive epilepsy.

Other factors which were associated with poor knowledge were absence of history of living with epileptic patient, poor attitude, stigma related to epilepsy and age range of $18-28$ and $29-36$. This finding was also supported by study in Ethiopia [8] and other systematic study conducted from Asian countries in which individual who have no experience of contact with epilepsy have poor knowledge [13].
Poor knowledge, stigma related to epilepsy, considering the cause of epilepsy as God punishment for sin and being elder were associated with unfavorable attitude towards epilepsy. It was in agreement with studies conducted in Ethiopia [8], Ismailia [41], Malaysia, UK and Thailand [13, 35-37]. The possible reason to this might be people with epilepsy are marginalized in society as a result of negative public attitudes towards Epilepsy. Epilepsy stigma, which is prevalent in cultures and backward laws in many places throughout the world has also negative consequences in developing countries including Ethiopia [32]. In Ethiopia, elderly population living in rural communities have still limited access to education which might lead to negative belief regarding epilepsy and most community residents believe cause of epilepsy related to punishment from the God for wrong doing.

\section{Limitations}

The first limitation of this study might be due to the cross-sectional nature of study design which cannot establish the temporal relationship between the dependent variable and its associated factors. Secondly, since the 
Table 5 Bivariate and multivariate logistic regression analysis of associated factors with Attitude towards Epilepsy among rural residents in Gedeo zone SNNPR, Ethiopia, $2019(n=732)$

\begin{tabular}{|c|c|c|c|c|c|}
\hline \multirow[t]{2}{*}{ Explanatory variables } & & \multicolumn{2}{|l|}{ Attitude } & \multirow[t]{2}{*}{ COR, $(95 \% \mathrm{Cl})$} & \multirow[t]{2}{*}{ AOR, $(95 \% C l)$} \\
\hline & & Unfavorable n(\%) & Favorable $\mathrm{n}(\%)$ & & \\
\hline \multirow[t]{5}{*}{ Educational status } & Cannot read and write & $118(16.1)$ & $78(10.7)$ & $3.36,(1.80,6.28)$ & $1.77,(0.86,3.64)$ \\
\hline & Primary & $152(20.8)$ & $124(16.9)$ & $2.74,(1.49,4.99)$ & $1.72,(0.87,3.40)$ \\
\hline & Secondary & $67(9.2)$ & $84(11.5)$ & $1.77,(0.93,3.37)$ & $1.71,(0.85,3.42)$ \\
\hline & Preparatory & $23(3.1)$ & $28(3.8)$ & $1.83,(0.83,4.00)$ & $1.40,(0.60,3.29)$ \\
\hline & College and above & $18(2.4)$ & $40(5.5)$ & Referent & Referent \\
\hline \multirow[t]{2}{*}{ Knowledge about epilepsy } & Good & $238(32.5)$ & $296(40.4)$ & Referent & Referent \\
\hline & Poor & $140(19.1)$ & $58(7.9)$ & $3.01(2.12,4.26)$ & $1.78(1.18,2.69)^{* *}$ \\
\hline \multirow[t]{2}{*}{ living with epileptic patients } & Yes & $17(2.3)$ & $32(4.4)$ & Referent & Referent \\
\hline & No & $361(49.3)$ & $322(44.0)$ & $2.11(1.15,3.87)$ & $1.71,(0.90,3.27)$ \\
\hline \multirow[t]{2}{*}{ God punishment for sin } & Yes & $168(22.9)$ & $106(14.5)$ & $1.87(1.38,2.54)$ & $1.81,(1.28,2.52)^{* *}$ \\
\hline & No & $210(28.7)$ & $248(33.9)$ & Referent & Referent \\
\hline \multirow[t]{2}{*}{ Stigma related to epilepsy } & Yes & $199(27.2)$ & $148(20.2)$ & $1.55(1.16,2.07)$ & $1.54,(1.11,2.15)^{*}$ \\
\hline & No & $179(24.5)$ & $206(28.1)$ & Referent & Referent \\
\hline \multirow[t]{4}{*}{ Age } & $18-28$ & $128(17.5)$ & $188(25.7)$ & Referent & Referent \\
\hline & 29-39 & $152(20.8)$ & 79 (10.8) & $2.83(1.99,4.02)$ & $2.14,(1.45,3.16)^{* *}$ \\
\hline & $40-50$ & $54(7.4)$ & $58(7.9)$ & $1.37(0.89,2.11)$ & $1.30(0.80,2.11)$ \\
\hline & $>50$ & $44(6.0)$ & $29(4.0)$ & $2.23(1.33,3.75)$ & $2.35(1.34,4.14)^{* *}$ \\
\hline \multirow[t]{2}{*}{ Monthly Income (ETB) } & $<1539 \mathrm{ETB}$ & $300(41)$ & $238(32.5)$ & $1.87(1.34,2.62)$ & $1.46,(0.99,2.16)$ \\
\hline & $\geq 1539 \mathrm{ETB}$ & 78 (10.7) & $116(15.8)$ & Referent & Referent \\
\hline
\end{tabular}

${ }^{*}=p$-value $<0.01,{ }^{* *}=p$-value $<0.05$

$\mathrm{n}(\%)=$ frequency and percentage

data was collected by face to face interview method, it might prone to social desirability bias especially in case of epilepsy stigma. Thirdly, the definition of epilepsy within a community might not allow the possibility of outgrowing epilepsy, since epilepsy was not defined in clinical terms as a result what participants think and perceive to be epilepsy based on their experience might not be potentially epilepsy.

\section{Conclusion}

There is a gap regarding the knowledge and attitude towards epilepsy among southern Ethiopia community residents. This demonstrates a need for community educational program regarding epilepsy which can increase community awareness particularly in rural areas to decrease stigma and negative beliefs towards epilepsy. Home visit and education focusing on epilepsy should be applied by health extension workers.

\section{Abbreviations}

AOR: Adjusted Odds Ratio; Cl: Confidence Interval; COR: Crude Odds Ratio; PLWE: People Living With Epilepsy; SNNRE: Southern Nation Nationalities and Regions of Ethiopia; WHO: World Health Organization

\section{Acknowledgments}

Authors would like to acknowledge, Dilla University for providing materials to duplicate questionnaires and giving ethical clearance. We also acknowledge Gedeo zonal health personnel (Manager) for giving official letter to identify number and distribution of study participants. Finally we thank participants for giving information during interview.

\section{Authors' contributions}

AM conceived the idea, wrote the proposal and participated in data collection, analysis, write up and revision of the manuscript. EH participated in data analysis, and revised subsequent drafts of the paper. BM and MM involved in data collection, analysis, writing up and final review of the manuscript. All authors read and approved this version of the manuscript to be considered for publication.

\section{Funding}

Not applicable.

\section{Availability of data and materials}

All raw data included in the manuscript can be accessed from the corresponding author through the email address of "alexmolla09@gmail.com" with rational request.

\section{Declarations}

Ethics approval and consent to participate

The study was ethically approved by the Institutional Review Board (IRB) of Dilla University. Permission letter was also obtained from Gedeo zone Health Bureau. Data was collected after obtaining written consent from participants and all information obtained was kept confidential during all stages of the study. The collected data were used only for the purpose of the study.

Consent for publication

Not applicable. 


\section{Competing interests}

All authors declare that they have no conflicts of interest.

\section{Author details}

'Department of Psychiatry, College of Health and Medical Science, Dilla University, Dilla, Ethiopia. ${ }^{2}$ Department of Reproductive health, College of Health and Medical Science, Dilla University, Dilla, Ethiopia.

\section{Received: 8 November 2019 Accepted: 18 February 2021}

\section{Published online: 27 February 2021}

\section{References}

1. Unwin N, Mugusi F, Aspray T, Whiting D, Edwards R, Mbanya J, et al Tackling the emerging pandemic of non-communicable diseases in subSaharan Africa: the essential NCD health intervention project. Public Health. 1999;113(3):141-6.

2. Aramyan L. Survey of parents of children with epilepsy in Yerevan, Armenia-knowledge, attitude, compliance with treatment. College of Health Sciences, American University of Armenia; 2005. p. 01-61.

3. Tran D-S, Odermatt P, Singphuoangphet S, Druet-Cabanac M, Preux P-M, Strobel M, et al. Epilepsy in Laos: knowledge, attitudes, and practices in the community. Epilepsy Behav. 2007;10(4):565-70.

4. Meinardi $H$, Scott R, Reis R, On Behalf Of The llae Commission on the Developing World JS. The treatment gap in epilepsy: the current situation and ways forward. Epilepsia. 2001;42(1):136-49.

5. Neligan A, Sander J. The incidence and prevalence of epilepsy. London: UCL Institute of Neurology; 2009.

6. Aydemir N. Familiarity with, knowledge of, and attitudes toward epilepsy in Turkey. Epilepsy Behav. 2011;20(2):286-90.

7. Obeid T. Stigma. An aspect of epilepsy not to be ignored. Saudi Med J. 2008:29(4):489-97.

8. Teferi J, Shewangizaw Z. Assessment of knowledge, attitude, and practice related to epilepsy: a community-based study. Neuropsychiatr Dis Treat. 2015;11:1239.

9. Njamnshi AK, Tabah EN, Bissek A-CZ-K, Yepnjio FN, Angwafor SA, Dema F, et al. Knowledge, attitudes and practices with respect to epilepsy among student nurses and laboratory assistants in the south west region of Cameroon. Epilepsy Behav. 2010;17(3):381-8.

10. Njamnshi AK, Angwafor SA, Tabah EN, Jallon P, Muna WF. General public knowledge, attitudes, and practices with respect to epilepsy in the Batibo Health District, Cameroon. Epilepsy Behav. 2009;14(1):83-8.

11. Shibre T, Alem A, Tekle-Haimanot R, Medhin G. Perception of stigma in people with epilepsy and their relatives in Butajira, Ethiopia. Ethiop J Health Dev. 2006:20(3):170.

12. Lua PL, Neni WS. Awareness, knowledge, and attitudes with respect to epilepsy: an investigation in relation to health-related quality of life within a Malaysian setting. Epilepsy Behav. 2011;21(3):248-54.

13. Lim KS, Lim CH, Tan CT. Attitudes toward epilepsy, a systematic review. Neurol Asia. 2011;16(4):269

14. Jacoby A. Stigma, epilepsy, and quality of life. Epilepsy Behav. 2002;3(6):1020.

15. De Boer HM, Mula M, Sander JW. The global burden and stigma of epilepsy. Epilepsy Behav. 2008;12(4):540-6

16. Beghi E, Berg A, Carpio A, Forsgren L, Hesdorffer DC, Hauser WA, et al. Comment on epileptic seizures and epilepsy: definitions proposed by the international league against epilepsy (ILAE) and the International Bureau for Epilepsy (IBE). Epilepsia. 2005;46(10):1698-9.

17. Gedefa M, Wolde T, Solomon G. Knowledge, attitudes and practices with respect to epilepsy among preparatory school students in Mekelle city, Ethiopia. Int J Collab Res Internal Med Publ Health. 2012;4(3):202.

18. FDRE $P$, Commission FDRoEPC. Summary and statistical report of the 2007 population and housing census: population size by age and sex. Addis Ababa: Population Census Policy; 2008.

19. Central stastical Agency E. Cences 2007 on southern nations nationalities and peoples' region; 2007

20. Eshete A, Taye F. Magnitude of severe head injury and its associated factors among head injury patients in gedeo zone, southern Ethiopia: a two-year retrospective study. Ethiop J Health Sci. 2018;28(3):323-30.

21. Negash YM. An assessment on the impact of road traffic accidents on human security in Gedeo zone (Ethiopia). J Stud Manage Planning. 2015; 1(5):18-37.
22. Mbuba CK, Abubakar A, Hartley S, Odermatt P, Newton CR, Carter JA. Development and validation of the Kilifi epilepsy beliefs and attitude scale. Epilepsy Behav. 2012;24(4):480-7.

23. Njamnshi AK, Tabah EN, Bissek A-CZ-K, Yepnjio FN, Kuate C, Angwafor SA et al. Knowledge, attitudes and practice with respect to epilepsy among secondary school students in the Kumbo west Health District-north west region-Cameroon. Epilepsy Behav. 2010;18(3):247-53.

24. Bozkaya IO, Arhan E, Serdaroglu A, Soysal AS, Ozkan S, Gucuyener K. Knowledge of, perception of, and attitudes toward epilepsy of schoolchildren in Ankara and the effect of an educational program. Epilepsy Behav. 2010:17(1):56-63.

25. Fernandes PT, Salgado PC, Noronha AL, Sander JW, Li LM. Stigma scale of epilepsy: validation process. Arq Neuropsiquiatr. 2007:65:35-42.

26. Ezeala-Adikaibe BA, Achor JU, Nwabueze AC, Agomoh AO, Chikani M, Ekenze OS, et al. Knowledge, attitude and practice of epilepsy among community residents in Enugu, south East Nigeria. Seizure. 2014;23(10):882-8.

27. Jack-Ide IO, Maliki AE, Onasoga O: Community members' perception of epilepsy and their attitude towards persons living with epilepsy disorders in a rural Community of Bayelsa State, Nigeria. https://doi.org/10.9734/INDJ/2 015/19472.

28. Babikar HE, Abbas IM. Knowledge, practice and attitude toward epilepsy among primary and secondary school teachers in South Gezira locality, Gezira state, Sudan. J Fam Community Med. 2011;18(1):17.

29. Saengsuwan J, Boonyaleepan S, Srijakkot J, Sawanyawisuth K Arunpongpaisal S, Chaiyakum A, et al. Public perception of epilepsy: a survey from the rural population in northeastern Thailand. J Neurosci Behavior Health. 2009;1(1):006-11.

30. Thien DD, Jallon P. Survey of public awareness, attitudes, and understanding toward epilepsy in Nhan Chinh, Hanoi, Vietnam, in 2003. Epilepsy Behav. 2006;8(1):176-80.

31. Alhazzani AA, Alqahtani AM, Abouelyazid A, Alqahtani AM, Alqahtani NA, Asiri KM, et al. Public awareness, knowledge, and attitudes toward epilepsy in the Aseer region, Saudi Arabia - a community-based cross-sectional study. Epilepsy Behav. 2016;63:63-6.

32. Tuan NA, Cuong LQ, Allebeck P, Chuc NTK, Tomson T. Knowledge attitudes and practice toward epilepsy among adults in BaVi, Vietnam: first report from the population-based EPIBAVI study. Epilepsia. 2007:48(10):1914-9.

33. Shehata GA, Mahran DG. Knowledge and attitude of epilepsy among secondary schools students (epileptic and non-epileptic) in Assiut city "Egypt". Epilepsy Res. 2011;95(1-2):130-5.

34. Shorvon S, Farmer P. Epilepsy in developing countries: a review of epidemiological, sociocultural, and treatment aspects. Epilepsia. 1988;29: S36-54.

35. Hasan SS, Allen Y, Wayne W, Ahmadi K, Anwar M, Goh G. Understanding of and attitudes toward epilepsy among the urban Chinese population in Malaysia. Singapore Med J. 2010;51(4):290.

36. Saengpattrachai M, Srinualta D, Lorlertratna N, Pradermduzzadeeporn E, Poonpol F. Public familiarity with, knowledge of, and predictors of negative attitudes toward epilepsy in Thailand. Epilepsy Behav. 2010;17(4):497-505.

37. McEwan L, Taylor J, Casswell M, Entwistle R, Jacoby K, Gorry J, et al. Knowledge of and attitudes expressed toward epilepsy by carers of people with epilepsy: a UK perspective. Epilepsy Behav. 2007;11(1):13-9.

38. Spatt J, Bauer G, Baumgartner C, Feucht M, Graf M, Mamoli B, et al. Predictors for negative attitudes toward subjects with epilepsy: a representative survey in the general public in Austria. Epilepsia. 2005;46(5): 736-42.

39. Neni SW, Latif AZA, Wong SY, Lua PL. Awareness, knowledge and attitudes towards epilepsy among rural populations in East Coast peninsular Malaysia: a preliminary exploration. Seizure. 2010;19(5):280-90.

40. Kabir M, lliyasu Z, Abubakar I, Kabir Z, Farinyaro A. Knowledge, attitude and beliefs about epilepsy among adults in a northern Nigerian urban community. Ann Afr Med. 2005;4(3):107-12.

41. Osama A, El Smahy MAEF, Moawad S. Public attitudes and knowledge toward epilepsy in Ismailia governorate. Egypt J Psychiatry. 2016;37(2):104.

\section{Publisher's Note}

Springer Nature remains neutral with regard to jurisdictional claims in published maps and institutional affiliations. 